\title{
Performansi Implementasi Numerik Metode Pseudo Spectral pada Model Gelombang 1D Boussinesq
}

\author{
Didit Adytia $^{\# 1}$ \\ School of Computing, Telkom University \\ Jl. Telekomunikasi 1, Bandung 40257, Indonesia \\ ${ }^{1}$ adytia@telkomuniversity.ac.id
}

\begin{abstract}
In the design of a numerical wave tank, it is necessary to use an accurate wave model as well as to choose an accurate and efficient numerical scheme for implementing the model. In this paper, we use a Pseudo-Spectral (PS) implementation for a wave model so called Variational Boussinesq Model. The implementation is aimed to obtain a higher time efficiency in the calculation of wave simulations. The performance of the PS implementation is compared in CPU-time with a Finite Element (FE) implementation of the wave model for simulating a focusing wave group. Results of both implementations give a good agreement with wave data from laboratory experiment. The PS-implementation is more efficient in computational time compared to the FE-implementation.
\end{abstract}

Keywords: Wave model, Boussinesq model, Pseudo spectral, numerical wave tank.

\begin{abstract}
Abstrak
Pada desain sebuah tangki gelombang numerik atau numerical wave tank, sangat diperlukan pemilihan yang tepat dari model gelombang, yaitu selain akurat, model tersebut harus diimplementasikan dengan skema numerik yang efisien. Pada paper ini digunakan metode numerik Pseudo Spectral (PS) untuk mengimplementasikan sebuah model gelombang yang dinamakan sebagai model Variational Boussinesq. Performansi dari implementasi metode numerik PS dalam hal efisiensi perhitungan dalam CPU-time akan dibandingkan dengan implementasi metode Finite Element (FE) dalam menyimulasikan fenomena gelombang fokus atau focusing wave group. Hasil dari kedua implementasi memperlihatkan kecocokan yang baik dengan data pengukuran gelombang dari percobaan fisik di laboratorium hidrodinamika. Implementasi metode PS memberikan efisiensi yang lebih baik dalam waktu komputasi dibandingkan dengan implementasi FE.
\end{abstract}

Kata Kunci: Model gelombang, model Boussinesq, Pseudo Spectral, tangki gelombang numerik. 
Didit Adytia

Performansi Implementasi Numerik Metode...

\section{PENDAhUluAN}

$\mathbf{U}$ ntuk mendukung perancangan struktur baik di lepas pantai maupun di pesisir pantai, sangat diperlukan pemahaman yang mendalam baik untuk perilaku gelombang maupun arus pada daerah tersebut. Salah satu cara untuk mempelajari perilaku gelombang dan efeknya terhadap sebuah struktur lepas pantai adalah dengan menyimulasikan gelombang dalam skala yang lebih kecil pada kolam gelombang atau yang disebut se-bagai wave tank pada laboratorium hidrodinamika. Salah satu contohnya adalah ketika perekayasa teknik pantai mendesain konfigurasi dari pemecah gelombang atau breakwater untuk sebuah pelabuhan. Efisiensi dari desain breakwater yang dibuat dapat di-pelajari terlebih dahulu dengan melakukan percobaan fisik pada wave tank 3D pada la-boratorium hidrodinamika, sehingga desain dari konfigurasi breakwater dapat dioptimalkan ketika diimplementasikan dalam bentuk pembangunan fisik pelabuhan yang sesungguhnya.

Namun demikian, eksperimen fisik dari gelombang pada wave tank sangat mahal dan memakan waktu yang tidak sedikit, terutama ketika pembuatan konfigurasi fisik dari breakwater maupun ketika mendesain gelombang yang diinginkan. Salah satu cara untuk melakukan efisiensi baik dari sisi biaya maupun waktu adalah dengan merekonstruksi eksperimen fisik di wave tank dengan simulasi gelombang secara numerik. Tentu saja model gelombang dan implementasi numerik yang digunakan harus mempunyai tingkat akurasi tinggi dan dapat dikomputasi secara cepat dan efisien. Implementasi numerik dari model gelombang yang dapat menyimulasikan gelombang seperti pada wave tank itu sendiri biasa disebut sebagai numerical wave tank.

Tipe model gelombang yang populer dipergunakan oleh perekayasa teknik pantai (coastal engineering) adalah model gelombang tipe Boussinesq. Pertama kali diperkenalkan oleh J. V. Boussinesq pada 1872, dan diperluas oleh Peregrine pada 1967 model gelombang tipe Boussinesq semakin dikembangkan seiring dengan meningkatnya ke-mampuan komputasi pada komputer. Dua model tipe Boussinesq yang paling banyak digunakan adalah model Boussinesq yang diperkenalkan oleh Madsen \& Sorensen [8] dan Nwogu [10]. Filosofi dasar dari penurunan persamaan Boussinesq adalah bagaimana menyederhanakan dinamika fluida dari gelombang yang berasal dari masalah 3 dimensi (3D) menjadi masalah 2D (yang hanya bergantung pada variabel horizontal saja) tanpa menghilangkan fenomena fisis dari gelombang seperti dispersi, nonlinearitas, shoaling, difraksi, refraksi dan sebagainya. Review tentang perkembangan tipe gelombang Boussinesq dapat ditemukan pada Brocchini [5], Madsen and Fuhrman [9]. Berbeda dengan tipe model Boussinesq pada umumnya, pada artikel ini kami akan mempergunakan model Boussinesq yang dinamakan sebagai Variational Boussinesq Model (lihat Adytia dan Lawrence [1], Adytia 2014 [2], dan Adytia 2012 [3] ).

Yang tidak kalah pentingnya dalam pembuatan numerical wave tank adalah implementasi numerik dari model gelombang tersebut. Selain harus mempunyai tingkat akurasi yang cukup tinggi, waktu perhitungan dari implementasi numerik tersebut sangat berperan dalam menentukan efisiensi dari numerical wave tank. Implementasi numerik yang paling umum dipakai dalam implementasi model gelombang diantaranya adalah Finite Difference Method (FDM), Finite Volume Method (FVM) dan Finite Element Method (FEM). Masingmasing implementasi mempunyai keunggulan dan kelemahannya. Pada artikel ini, berbeda dari implementasi numerik di atas, kami menggunakan implementasi numerik yang dinamakan sebagai Pseudo Spectral Method (PSM) untuk mengimplementasikan model gelombang VBM. Kemudian perfomansi dari implementasi PSM ini akan dibandingkan dengan implementasi FEM.

Isi dari paper ini adalah sebagai berikut. Pada bagian kedua akan dijelaskan tentang model gelombang VBM, yang akan dilanjutkan dengan penjelasan dan teknik implementasi model tersebut dengan menggunakan PSM pada bagian ketiga. Pada bagian keempat, akurasi dan performansi dari implementasi VBM dengan PSM akan dites dengan cara membandingkan hasil simulasi dengan data eksperimen fenomena gelombang fokus (focusing wave group) yang dilakukan pada laboratorium hidrodinamika. Pada bagian terakhir akan disimpulkan tentang performansi dari implementasi numerik PSM pada model VBM. 


\section{TINJAUAN PUSTAKA}

Berbeda dengan model gelombang Boussinesq Madsen \& Sorensen [8] dan Nwogu [10] yang mempunyai turunan spatial yang tinggi (sampai dengan orde ke-6), pada model Variational Boussinesq Model (VBM) turunan parsial tertinggi pada persamaan pembangkitnya (governing equations) adalah hanya sampai dengan orde ke-2. Selain itu, persamaan VBM tergolong relatif sederhana jika dibandingkan model Boussinesq lainnya, sehingga implementasi numerik dari model ini relatif mudah. Namun demikian, berbeda dengan model Boussinesq lainnya yang hanya mempunyai 2 persamaan, yaitu persamaan continuity dan momentum, pada VBM terdapat 1 persamaan tambahan, yaitu persamaan eliptik (sehingga total terdapat 3 persamaan yang harus diselesaikan pada setiap time-step).

Persamaan VBM diturunkan berdasarkan metode variasi (variational method) yang pertama kali diperkenalkan secara independen oleh Zakharov [11] dan Broer [4], yang menyatakan bahwa fenomena gelombang dapat dinyatakan dalam suatu sistem yang dinamakan sistem persamaan Hamiltonian. Hamiltonian sendiri adalah total energi, yaitu jumlah energi kinetik dan energi potensial. Seperti yang di deskripsikan pada Adytia [2] dan Adytia \& Lawrence [1], pada penurunan model VBM, variabel 3D fluid potential $\Phi(x, y, z, t)$ dihampiri dengan nilai fluid potential pada permukaan air yaitu $\phi(x, y, t)$ dan sebuah kombinasi linear dari suatu fungsi vertikal $F_{m}(z)$ dan sebuah fungsi tambahan yang bergantung pada koordinat horizontal $\psi_{m}(x, y, t)$ yaitu sebagai berikut

$$
\Phi(x, y, z, t)=\phi(x, y, t)+\Sigma_{m} F_{m}(z) \cdot \psi_{m}(x, y, t)
$$

Disini $x, y$ dan $z$ menyatakan koordinat horizontal dan vertikal, dan t menyatakan waktu. Seperti yang dijelaskan pada Adytia 2012 [3], dengan mensubtitusikan approksimasi di atas ke dalam ekspresi fungsional kinetik energi dan melakukan turunan variasi pada persamaan Hamiltonian, didapatlah dua persamaan (continuity dan momentum) untuk VBM yaitu sebagai berikut:

$$
\begin{aligned}
& \partial_{t} \eta=-\partial_{x}\left[(h+\eta) \partial_{x} \phi+\beta \partial_{x} \psi\right] \\
& \partial_{t} \phi=-g \eta-\left(\partial_{x} \phi\right)^{2} / 2
\end{aligned}
$$

dan persamaan eliptik untuk mendapatkan nilai dari $\psi$

$$
-\partial_{x}\left(\alpha \partial_{x} \psi\right)+\gamma \psi=\partial_{x}\left(\beta \partial_{x} \phi\right)
$$

Disini $\eta$ menyatakan elevasi muka air yang dihitung dari $z=0$, h menyatakan kedalaman dari air, sedangkan $\alpha, \beta$ dan $\gamma$ adalah nilai yang bergantung pada fungsi ketinggian $F$ dan bergantung secara tidak langsung terhadap $\eta$ dan $h$ (lihat Adytia 2012 [3]).

Persamaan di atas dapat dihitung sebagai berikut.

1. Untuk nilai awal yang diberikan (initial conditions) $\eta_{0}$ dan $\phi_{0}$, kita hitung nilai $\alpha, \beta$ dan $\gamma$ kemudian dicari $\psi_{0}$ dengan cara memecahkan persamaan eliptik (3).

2. Masukkan nilai awal $\eta_{0}, \phi_{0}$ dan $\psi_{0}$ pada persamaan (1) dan (2), kemudian evolusikan terhadap waktu dengan cara melakukan integrasi terhadap waktu dengan menggunakan Runge-Kuta orde 4.

3. Dengan didapatnya nilai terbaru untuk $\eta, \phi$ dan $\psi$, langkah 1 dan 2 di atas dapat di ulangi sampai dengan waktu yang dinginkan.

Pada Adytia 2014 [2] dan Adytia \& Lawrence [1], sistem persamaan VBM di atas telah diimplementasikan dengan Finite Element Method (FEM) dengan menggunakan basis fungsi linear, yaitu tent-function. Pada artikel ini persamaan (1) dan (2) di atas akan diimplementasikan secara numerik dengan Pseudo-Spectral Method (PSM) untuk mempercepat waktu komputasi. Efisiensi waktu komputasi pada PSM dapat dicapai dikarenakan pada PSM hanya memanfaatkan transformasi Fourier dan invers transformasi Fourier dalam menghitung suku-suku pada persamaan yang dihitung. Pada bagian selanjutnya akan dijelaskan tentang PSM dan implementasi dari VBM dengan menggunakan PSM. 
Didit AdyTiA

Performansi Implementasi Numerik Metode...

\section{IMPLEMENTASI PSEUDO SPECTRAL METHOD}

Ide dasar dari Pseudo-Spectral Method (PSM) untuk memecahkan suatu persamaan diferensial parsial atau PDE adalah melakukan perhitungan turunan spasial pada PDE di ruang Fourier dengan memanfaatkan transformasi Fourier dan invers transformasi Fourier. Sedangkan untuk operasi perkalian pada suku-suku nonlinear dilakukan pada ruang Real (lihat Fornberg [6]). Sebelumnya, kita definisikan Transformasi Fourier (FT) and Invers dari Transformasi Fourier (IFT) sebagai berikut.

Definisi 3.1. Transformasi Fourier dari suatu fungsi $\theta(x, t)$ didefinisikan sebagai berikut

$$
\hat{\theta}(k, t):=\mathcal{F}\{\theta(x, t)\}=\int_{-\infty}^{\infty} \theta(x, t) e^{i k x} d x
$$

Sedangkan Invers dari Transformasi Fourier dari fungsi $\hat{\theta}(k, t)$ adalah

$$
\theta(x, t):=\mathcal{F}^{-1}\{\hat{\theta}(k, t)\}=\frac{1}{2 \pi} \int_{-\infty}^{\infty} \hat{\theta}(k, t) e^{-i k x} d k
$$

dengan $k$ adalah bilangan gelombang (wave number) yang berelasi dengan domain spasial $x$.

Pada PSM, turunan spasial dari suatu fungsi $\theta(\mathrm{x}, \mathrm{t})$ dapat dicari dengan cara sebagai berikut

$$
\frac{\partial^{n}}{\partial x^{n}}[\theta(x, t)] \leftrightarrow \mathcal{F}^{-1}\left\{(i k)^{n} \mathcal{F}(\theta(x, t)) \quad\right\}
$$

dimana $i$ adalah unit bilangan imajiner dan $k$ adalah bilangan gelombang. Dengan menggunakan definisi di atas maka implementasi PSM untuk persamaan (1) dan (2) dari VBM dituliskan sebagai berikut

$$
\begin{aligned}
& \partial_{t} \eta=-\mathcal{F}^{-1}\left(i k \mathcal{F}\left[(h+\eta) \mathcal{F}^{-1}\{i k \mathcal{F}\{\phi\}\}-\beta \mathcal{F}^{-1}\{i k \mathcal{F}\{\psi\}\}\right]\right) \\
& \partial_{t} \phi=-g \eta-\left[\mathcal{F}^{-1}(i k \mathcal{F}\{\phi\})\right]^{2} / 2
\end{aligned}
$$

Perhatikan bahwa definisi and implementasi PSM di atas adalah menggunakan integral Fourier pada domain $(-\infty, \infty)$ serta fungsi-fungsi yang dikenakan operator tersebut diasumsikan bersifat periodik. Pada realisasi implementasi numeriknya pada code numerik, integral di atas harus dihitung pada domain yang berhingga, sehingga yang akan digunakan dalam komputasi adalah Transformasi Fourier Diskrit (Discrete Fourier Transform atau DFT) dan invers nya.

Secara umum, solusi $\eta$ dan $\phi$ tidak bersifat periodik. Namun demikian untuk dapat menerapkan metode PSM pada VBM, solusi-solusi tersebut dapat dibuat periodik dengan cara membuat solusi-solusi tersebut bernilai nol pada batas domain komputasi. Dengan kata lain solusi $\eta$ dan $\phi$ di redam atau damping dengan menggunakan suatu fungsi karakteristik $\chi(x)$, yang merupakan suatu fungsi smooth yang bernilai nol pada domain komputasi dan bernilai 1 pada ujung batas komputasi. Penerapan peredaman pada VBM dengan fungsi $\chi(x)$ dapat dilakukan dengan menambahkan suku redaman pada pers. (1) dan (2) dengan cara sebagai berikut

$$
\begin{aligned}
& \partial_{t} \eta=-\partial_{x}\left[(h+\eta) \partial_{x} \phi+\beta \partial_{x} \psi\right]-\chi \cdot \eta \\
& \partial_{t} \phi=-g \eta-\left(\partial_{x} \phi\right)^{2} / 2-\chi \cdot \phi
\end{aligned}
$$

Illustrasi dari efektifitas redaman fungsi $\chi(x)$ dapat dilihat Gambar 1. Terlihat bahwa gelombang teredam ketika menyentuh area redaman. Dengan meredam solusi pada batas-batas domain komputasi, maka efek periodisitas dari solusi dapat dihindari.

Perhatikan bahwa pada pers. (4) dan (5) telah diimplementasi dengan PSM. Namun demikian, penerapan PSM pada pers. (3) yaitu persamaan eliptik untuk mencari $\psi$ akan menghasilkan sistem persamaan linear dalam bentuk persamaan matriks yaitu 


$$
L \underline{\psi}=\underline{b}
$$

dimana $L$ adalah full matriks (yang terisi penuh), $\underline{\psi}$ adalah vektor $\psi$ pada grid komputasi dan $\underline{b}$ adalah vektor pada ruas kanan pers. (3). Dikarenakan matriks $L$ yang bersifat penuh, maka pencarian solusi $\underline{\psi}$ akan cukup memakan waktu. Namun, jika pers. (3) diimplementasikan dengan Finite Element Method $\overline{\text { dengan fungsi }}$ basis linear, maka matriks $L$ pada pers. (8) adalah matriks tridigonal yang simetrik. Dengan alasan efisiensi dari waktu komputasi ini, maka pers. (3) dipecahkan dengan FEM. Bentuk dari matriks $L$ dan vektor $\underline{b}$ hasil implementasi FEM dapat dilihat pada Adytia 2012 [3].
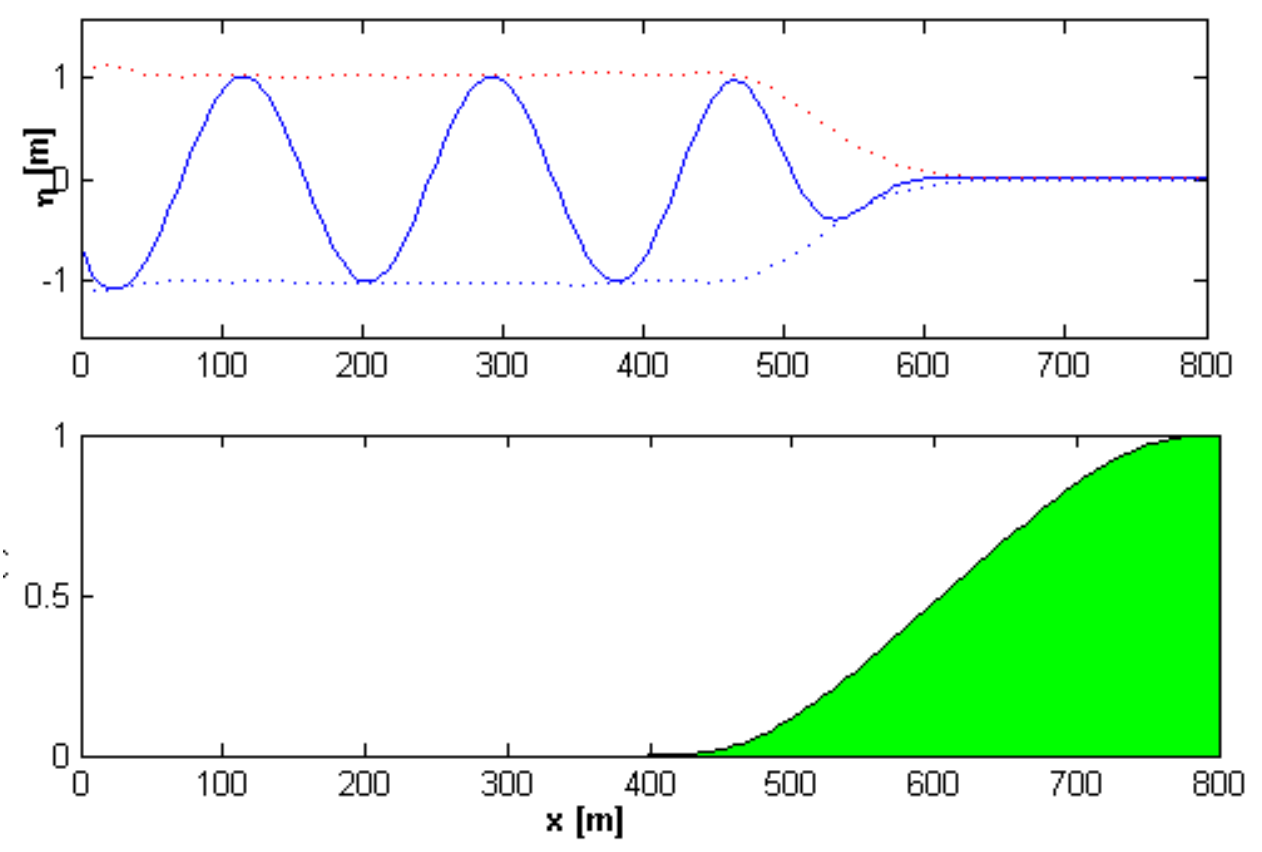

Gambar 1. Pada bagian atas adalah snapshot dari simulasi gelombang monokromatik (garis biru) dengan arah propagasi ke kanan. Bagian bawah menggambarkan fungsi karakteristik untuk redaman $\chi(x)$, dimana daerah redaman digambarkan oleh daerah yang berwarna hijau.

Untuk menyelidiki tingkat efisiensi dan akurasi dari implementasi PSM, maka pada bagian empat artikel ini akan dibandingkan performansi implementasi PSM dengan implementasi FEM dalam menyimulasikan fenomena gelombang fokus atau focusing wave group.

\section{SIMULASI FENOMENA GELOMBANG FOKUS}

Untuk menyelidiki tingkat akurasi dan efisiensi waktu komputasi dari implementasi dengan PSM, pada paper ini dilakukan rekonstruksi percobaan fisik pada wave tank yang menyimulasikan focusing wave group (FWG). Eksperimen fisik tersebut dilakukan oleh laboratorium hidrodinamika MARIN (Maritime Research Institute Netherlands) di Wageningen, Belanda, dengan nomer eksperimen 101013. Data eksperimen ini sebelumnya telah dipakai untuk simulasi numerik model VBM dengan implementasi FE pada Adytia 2012 [3]. Eksperimen tersebut dilakukan pada wave tank dengan panjang $120 \mathrm{~m}$ dan dengan kedalaman $1 \mathrm{~m}$. Sketsa dari wave tank untuk eksperimen FWG diilustrasikan pada Gambar 2, dimana gelombang dibangkitkan oleh pembangkit gelombang (wave flap) pada lokasi $x=0 m$ dan signal propagasi gelombang diukur pada lokasi $\mathrm{W}_{1}=10 \mathrm{~m}$ dan $\mathrm{W}_{5}=50 \mathrm{~m}$ dengan menggunakan wave buoy. 
Didit Adytia

Performansi Implementasi Numerik Metode...

Pada fenomena gelombang fokus FWG, gelombang yang mempunyai panjang gelombang yang lebih kecil dipropagasikan terlebih dahulu, yang disusul oleh gelombang yang lebih panjang. Signal yang diukur pada $\mathrm{W}_{1}$ ditunjukkan pada Gambar 3. Akibat dari sifat fisis dari gelombang yang bersifat dispersif, maka gelombanggelombang pendek yang didepan tersebut pada akhirnya akan disusul oleh gelombang panjang (yang berpropagasi lebih cepat), sehingga pada waktu dan tempat tertentu terjadilah gelombang fokus yang membentuk gelombang yang sangat tinggi jika dibandingkan dengan apa yang dibangkitkan pada wave flap.
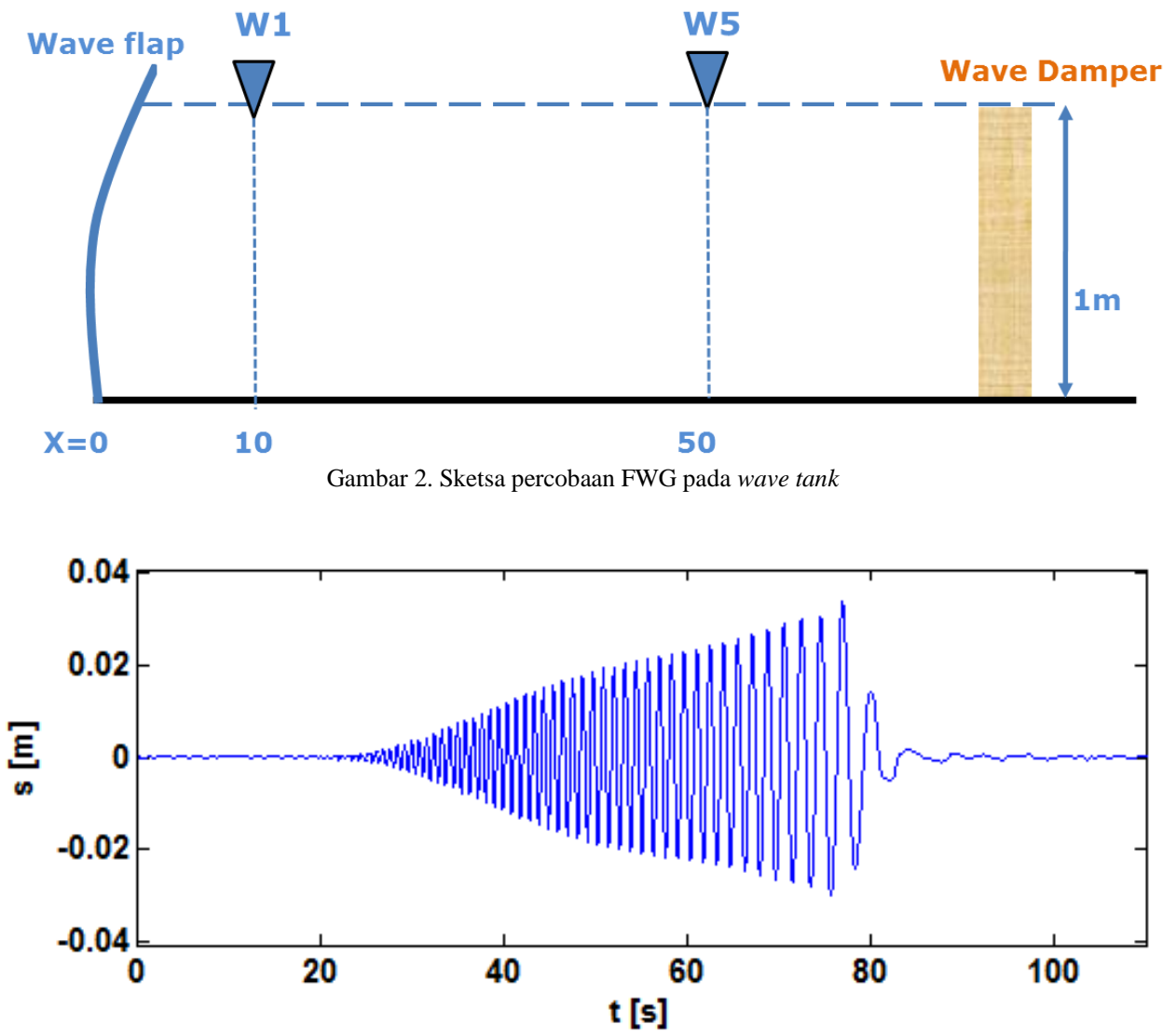

Gambar 3. Signal pengukuran dari data eksperimen FWG pada lokasi $\mathrm{W}_{1}=10 \mathrm{~m}$.

Untuk melakukan simulasi FWG, signal pada $\mathrm{W}_{1}$ digunakan sebagai influks untuk simulasi. Pada simulasi ini digunakan grid uniform dengan lebar grid $d x=0.075 m$, dengan domain simulasi $x \in[0,90 m]$. Pada Gambar 4, snapshot dari simulasi pada berbagai waktu $t$ ditunjukkan, dimana garis merah putus-putus menunjukan ketinggian gelombang maksimum setiap saat.

Pada Gambar 5, ditunjukkan perbandingan signal antara hasil simulasi dan hasil eksperimen pada lokasi $\mathrm{W}_{5}=50 \mathrm{~m}$, yaitu pada saat terjadinya wave focusing. Perhatikan bahwa signal yang awalnya hanya mempunyai ketinggian $0.04 m$ pada $\mathrm{W}_{1}$ (Gambar 3), pada saat terjadi wave focusing menjadi $0.25 \mathrm{~m}$ di $\mathrm{W}_{5}\left(\mathrm{Gambar}_{5}\right)$ atau menjadi 6.25 kali lebih tinggi. Hasil perbandingan antara hasil simulasi dan data eksperimen menunjukkan tingkat akurasi yang cukup tinggi dengan nilai korelasi mencapai 0.96 (nilai korelasi adalah antara 0 dan 1 , dimana 1 menunjukkan korelasi yang tertinggi) untuk implementasi dengan PSM, dan 0.95 untuk implementasi FEM.

Untuk mengukur waktu komputasi, kami menggunakan komputer dengan processor Intel Xeon 3.6Gb dengan RAM 16GB pada Operating System Windows 10, dimana komputasi untuk simulasi FWG dengan implementasi PSM diselesaikan dalam waktu 51s, sedang dengan implementasi FEM diselesaikan dalam 
waktu 99.5s. Dengan kata lain implementasi PSM memberikan waktu lebih singkat sampai dengan 2 kali dibandingkan dengan implementasi FEM.

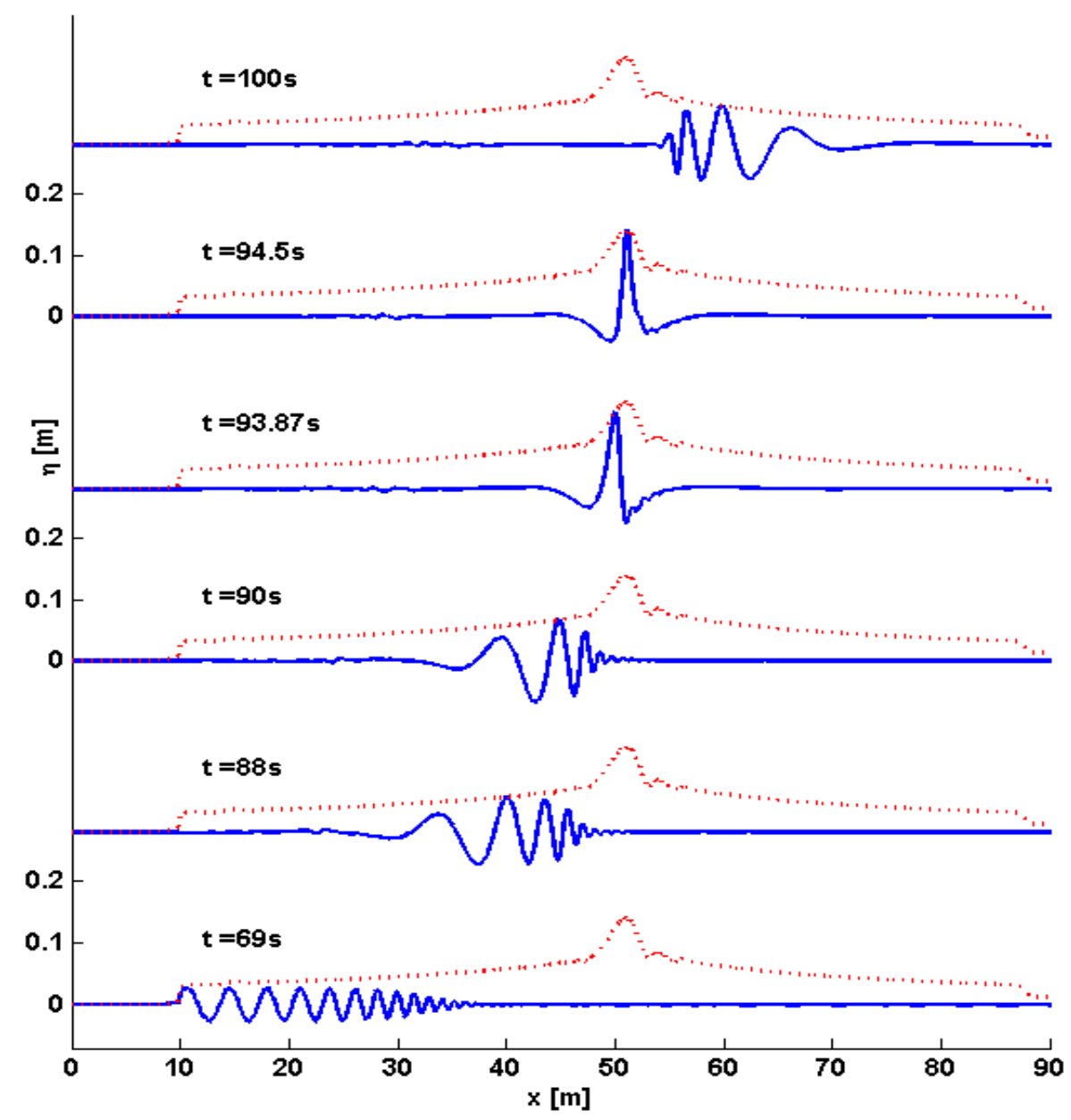

Gambar 4. Snapshot dari simulasi gelombang (garis biru) pada beberapa waktu simulasi $t$. 
Didit AdyTiA

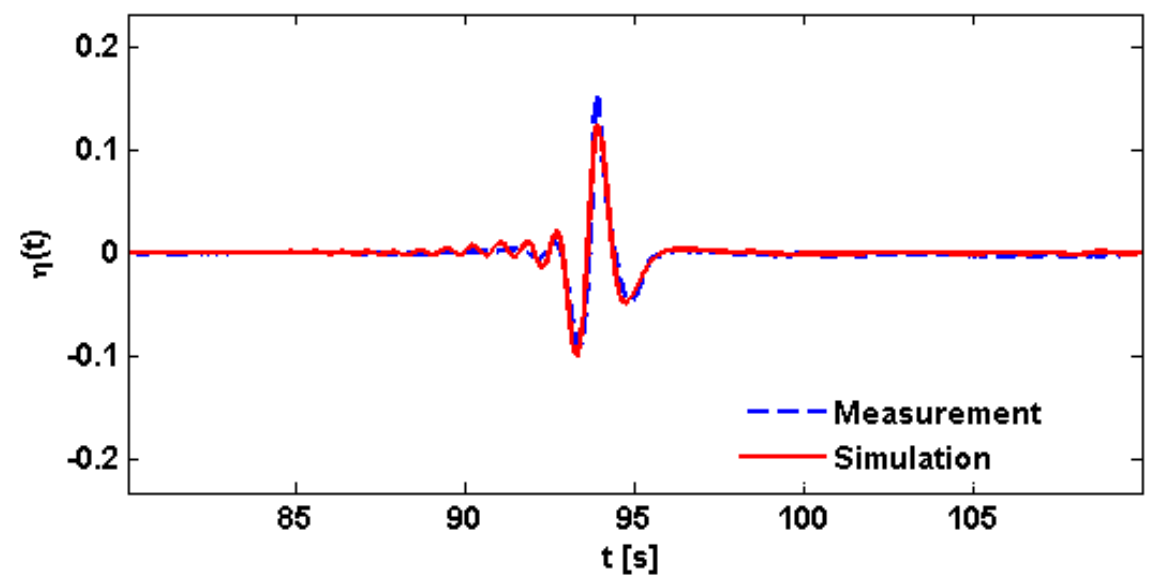

Gambar 5. Perbandingan signal dari data eksperimen (garis biru putus-putus) dan hasil simulasi (garis merah) pada saat $t=50 s$.

\section{KESIMPULAN}

Implementasi numerik Pseudo-Spectral Method (PSM) termasuk salah satu implementasi yang sangat sederhana untuk digunakan dan sangat efisien dari segi waktu komputasi. Namun demikian, dikarenakan menggunakan tranformasi Fourier yang mengharuskan kondisi batas yang periodik, PSM dinilai kurang praktis dan kurang efisien terutama ketika digunakan untuk menyimulasikan domain komputasi yang kompleks dan tidak periodik. Hal ini sebenarnya dapat diatasi dengan melakukan peredaman gelombang (solusi) pada kondisi batas ketika menerapkan PSM pada model gelombang. Untuk perancangan sebuah numerical wave tank, dimana domain wave tank biasanya berbentuk sederhana, selain akurat, metode PSM dapat menjadi sangat efisien dari sisi waktu komputasi. Pada paper ini telah dilakukan komputasi untuk simulasi FWG dengan implementasi PSM yang dicapai dalam waktu waktu 51s, sedang dengan implementasi FEM dicapai dalam waktu 99.5s. Dengan kata lain implementasi PSM memberikan waktu lebih singkat sampai dengan 2 kali dibandingkan dengan implementasi FEM.

\section{DAFTAR PUSTAKA}

[1] Adytia, D., Lawrence. Fully nonlinear dispersive HAWASSI-VBM for coastal zone simulations. In Proc. of the ASME 2016 35th International Conference on Ocean, Offshore and Archtic Engineering OMAE 2016, 2016.

[2] Adytia, D., Simulations of short-crested harbor waves with variational Boussinesq modelling. In Proc.24th Int. Ocean and Polar Engineering Conference. ISOPE 2014, ISOPE, pp. 912-918., 2014.

[3] Adytia, D., "Coastal zone simulations with Variational Boussinesq Modelling”. PhD Thesis. University of Twente, The Netherlands., 2012.

[4] Broer, L., On the Hamiltonian theory of surface waves. Appl. Sci. Res., 29(1), pp. 430-446, 1974.

[5] Brocchini,M., A reasoned overview on boussinesqtype models: the interplay between physics, mathematics and numerics. In Proc. $R$ Soc A., Vol. 469 of Series name, Royal Society Publishing, p. 20130496, 2013.

[6] Fornberg, B., "A practical guide to pseudospectral methods". Cambridge: Cam-bridge University Press, 1996.

[7] J. C. Luke. A variational principle for fluid with a free surface. J. Fluid Mech., 27: 395-397, 1967.

[8] Madsen, P.A. and Sørensen, O.R. , A new form of the Boussinesq equations with improved linear dispersion characteristics. Part 2: A slowly-varying ba-thymetry, Coast. Eng. Vol 18, pp 183-204., 1992.

[9] Madsen, P.A. and Fuhrman, D.R., "Advances in Numerical Simulation of Nonlinear Water Waves, Chapter Higher-order Boussinesq-type modelling of non-linear wave phenomena in deep and shallow water", World Scientific, pp 245-285. (Advances in Coastal and Ocean Engineering; 11), (2010).

[10] Nwogu, O., Alternative form of Boussinesq equations for nearshore wave propagation. J. Waterw. Port Coast. Ocean Eng. Vol 119, pp 618-638., 1993.

[11] Zakharov, V., Stability of periodic waves of finite amplitude on the surface of a deep fluid. J. Eppl. Mech.Tech. Phys., 9(2), pp. $190-194,1968$. 